\title{
A DISTRIBUTED MEASUREMENT SYSTEM TO ESTIMATE PLANT WATER CONTENT IN AGRICULTURAL FIELDS BASED ON WIRELESS SENSOR NETWORKS
}

\author{
João C. Giacomin* \\ Elson J. Silva ${ }^{\dagger}$ \\ ${ }^{*}$ DCC-UFLA \\ Caixa Postal 3037 \\ CEP 37200-000 - Lavras - MG \\ ${ }^{\dagger}$ DEE-UFMG \\ Av. Antônio Carlos, 6627
}

Flávio H. Vasconcelos ${ }^{\dagger}$

CEP 31270-010 - Belo Horizonte - MG

\section{RESUMO}

Neste artigo é proposto um sistema distribuído de medição baseado em uma rede de sensores sem fios (RSSF) empregado na estimação do teor de água de vegetação em campos agrícolas. Uma RSSF instalada por todo o campo permite medir e mapear as variáveis de solo, de ar e de plantas e transmitir esses dados, através de pequenos rádios, até um computador central. O conteúdo de água é obtido pela medição da atenuação dos sinais (RF) de comunicação da rede, sem se utilizar qualquer sensor dedicado a esta finalidade. É apresentada a importância de se fazer medição distribuída para se estimar parâmetros de culturas agrícolas. Um modelo de propagação de ondas de rádio através da vegetação é utilizado como base para o desenvolvido do método de estimação do conteúdo de água da vegetação através da RSSF. Resultados experimentais confirmam a viabilidade da proposta.

PALAVRAS-CHAVE: medição distribuída, redes de sensores sem fios, teor de água de vegetação, atenuação de ondas de

\footnotetext{
Artigo submetido em 10/06/2006

1a. Revisão em 22/01/2008

2a. Revisão em 29/09/2008

Aceito sob recomendação do Editor Associado

Prof. José Reinaldo Silva
}

rádio.

\section{ABSTRACT}

This paper proposes a distributed measuring system based on wireless sensor networks (WSN) employed to estimate vegetation water content in agricultural fields. A WSN deployed along the whole field permits to measure and map soil, air and plant variables and transmit these data, by small radios, to a central computer. Water content is obtained by measuring the attenuation of the network communication signals (RF), without the use of any specific sensor. The need of distributed measurements to estimate agricultural crop parameters is pointed out. A mathematical model of radio wave propagation through vegetation is used to develop the method of estimating vegetation water content with a RSSF. Field tests confirmed the viability of the proposal.

KEYWORDS: distributed measurement, wireless sensor network, vegetation water content, radio wave attenuation. 


\section{INTRODUCTION}

A Wireless Sensor Network (WSN) is a distributed measurement system with applications in many areas: military, commercial, scientific (environmental monitoring), industrial, agricultural and others (Heidemann \& Govindan, 2004; Beckwith et al., 2004). This system is composed by a great number of autonomous devices, which communicate to each other in a non guided mode (normally by radios) forming a network. These devices, denominated sensor nodes, execute measurements in the environment and transmit the collected data via the network to an access point connected to a computer, which serves as a data base. Sensor nodes are equipped with memory and processing units and are battery powered. The WSN protocols and the sensor node operation mode are oriented to energy efficiency, so that they can operate for periods over a year without human intervention.

WSN is an interesting tool which can be used in crop fields for precision agriculture (PA) or precision farming processes. PA is a management method for large agricultural fields which considers the specific needs of each particular place inside the field (Magri et al., 2005). Traditional management techniques that apply uniform treatment are not adequate for large crop fields because their characteristics change in time and space (National Research Council, 1997). Soil attributes (moisture, quantity of nutrients, etc), plant diseases and productivity vary a lot from one area to another on one and the same field (Mallarino \& Wittry, 2004). In order to carry out this management process, it is necessary to measure soil, plant and air variables in various spots on the field (Hatfield, 2000).

Agricultural field figures can be obtained either by direct measurements with sensors placed close to the soil, or by remote sensing with sensors placed in aircrafts or satellites (Leon et al., 2003). In remote sensing data are obtained from the electromagnetic wave reflected by soil and vegetation, especially in the bands of visible light, infra-red and microwaves (Hornbuckle, 2003). Microwaves' reflection and absorption are strongly affected by soil and vegetation water content, making it possible to estimate these characteristics with the help of radiometric sensors. However, conducting the measurements at land level is advantageous over remote sensing, since it is not affected neither by weather nor field surface conditions (Adamchuk et al., 2004). Besides, larger amount of data with better resolution in space and time can be obtained at land level if a large number of special purpose sensors is used. Different environmental variables are measured with sensors placed in the field and are transmitted by a wireless sensor network to a central computer, even at night. The collected data are then used in decision making processes for the field management.
This paper is organized as follows. Section 2 describes how a WSN can be used to map vegetation water content in a field. A model for electromagnetic waves propagation in vegetation situated between a pair of sensor nodes is presented in section 3. Section 4 describes the model that relates radio wave attenuation to vegetation water content. Section 5 presents a method to calculate the radio wave attenuation factor $(\alpha)$ using the model described in section 3. A methodology for the measurement process is described in section 6. Section 7 presents some experimental results obtained from measurements in corn fields, which confirm the proposed theory. Conclusions are presented in section 8 .

\section{WSN AS A MEASUREMET TOOL}

This work is about a vegetation water content estimation system applied in agriculture, which uses the communication radio (RF) signals of a WSN. While the WSN works to measure and transmit data related to agricultural variables, acting as an element of the precision agriculture process, radio signals passing through vegetation will be measured in all sensor nodes to estimate plant water content. Plant water content is important in the control of growing process and its identification is a difficult task.

We propose here to estimate plant water content in the field (no need to collect plant samples) without the use of an additional specific sensor connected to the wireless sensor network. This estimation process is based on the received signal strength information (RSSI) available in the radios of all sensor nodes. The method proposed here is different from traditional remote sensing because a distributed measurement system and low cost radios with non directional antennas are used.

A WSN acting as a distributed measurement system can be used to capture data from many areas all over the crop field. The average value obtained by several measurements made by a group of sensor nodes occupying a specific area in the field is considered useful information about the vegetation present in that area. The detection of less water in one area of the field compared to the others can be used to indicate that some problem exists in the soil-plant system in that area. The periodic measurement of the vegetation water content can be used to estimate variations in plant hydric potential during day and night.

Distributed measurement of plant water content provides more representative values for agriculturists working with precision-farming than values obtained from a single measurement in one spot, even if taken by more accurate equipment. Although the WSN nodes are deployed at equal distances to each other, radio signal attenuation may be different depending on the ways of communication (for different pairs 
of nodes). This is due to the non uniform plant distribution and because vegetation is not seen as a homogeneous dielectric. Besides that, soil and plant characteristics in a certain area vary around a mean value (Bakhsh et al., 2000; Magri et al., 2005) with a certain probability density function. A more representative value for vegetation characteristics is obtained when one considers an average value out of a set of measurements carried out in distinct sposts in one area of a crop field (Giacomin \& Vasconcelos, 2006a). This points to the adoption of WSN as an appropriate tool for agricultural measurements.

\section{PROPAGATION MODEL}

Models for microwave propagation are derived from Maxwell equations (Schnell, 1993). A first choice is to use the Friis transmission formula, which describes the electromagnetic wave propagation in free space (Ulaby et al., 1981):

$$
\frac{P_{R}}{P_{T}}=\left(\frac{\lambda}{4 \pi d}\right)^{2} G_{T} G_{R}=\frac{1}{L_{F S}} G_{T} \cdot G_{R}
$$

where $P_{R}$ and $P_{T}$ are the received and transmitted power, $G_{T}$ and $G_{R}$ are the transmitter and receiver antenna gains, $\lambda$ stands for the wave length and $d$ is the distance between the radios, transmitter and receiver. $L_{F S}$ is "free space transmission loss".

This model is used by WSN researchers for location discovery purpose (Lymberopoulos et al., 2005; Bulusu et al., 2004). To estimate the relative position of a given node inside the WSN, the nodes are programmed with an algorithm based on the relation between received power $\left(P_{R}\right)$ and distance $(d)$ :

$$
\frac{P_{R}}{P_{R 0}}=\frac{1}{d^{2}}
$$

Here, $P_{R 0}$ is a reference value, obtained for unitary distance and for propagation in free space.

When signal propagation of radio communication occurs inside vegetation, like in agricultural crops, an additional attenuation will appear. This attenuation is represented as an exponential function:

$$
\frac{P_{R}}{P_{R 0}}=\frac{e^{-2 . \alpha . d}}{d^{2}}=e^{-2 . \alpha . d} \cdot d^{-2}
$$

where $\alpha$ is denominated absorption factor or absorption coefficient of microwaves by vegetation, which is strongly affected by vegetation water content.
Tavakoli et al. (1991), Le Vine \& Karam (1996) and Ulaby $\&$ Wilson (1985) used directional radars to study the influence of vegetation on microwave (RF) signals attenuation. Then, they considered only the attenuation caused by vegetation, neglecting dispersion due to distance between transmitter and receiver. Here, a more complex model is needed because a cheaper and simpler equipment is used, which employ monople antennas whose RF signal propagates in almost all directions.

The model described in equation (3) considers just one propagation path, the LOS (line of sight), that is the unique pass when the communication occurs in free space. When transmitter $(T x)$ and receiver $(R x)$ are placed close to soil or another reflective surface, a more accurate model to describe radio signal attenuation is needed. This model considers the interaction between two electrical fields that reaches receiver antenna, a field of LOS signal and a field of reflected signal. The first one is denominated electrical field from the direct propagation signal $\left(E_{d}\right)$, and the second one is denominated electrical field from the reflected signal $\left(E_{r}\right)$. The electrical field on the receiver's antenna, denominated total electrical field $\left(E_{t}\right)$, results from the interaction of $E_{d}$ and $E_{r}$, as described in equation (4) and is represented graphically in figure 1 in phasor form.

$$
E_{t}=\sqrt{\left(E_{d}+E_{r} \cdot \cos (\delta)\right)^{2}+\left(E_{r} \cdot \operatorname{sen}(\delta)\right)^{2}}
$$

Here, $\delta$ is the difference in the phases of $E_{d}$ and $E_{r}$ :

$$
\delta=\frac{2 \cdot \pi}{\lambda} \cdot(r-d)
$$

where $r$ is the propagation distance of the signal reflected by the soil and $d$ is the distance of direct (LOS) signal propagation. One can observe that always $r>d$.

Figure 1 represents graphically two propagation paths between two nodes of a WSN, which were installed at distance $d$ from each other and height $h$ from soil surface. $\theta$ is the propagation angle relative to the antenna and is used to calculate antenna directivity $(D) . \psi$ is the angle of incidence relative to soil surface and is used to calculate soil reflectivity $(R)$.

Considering the signal dispersion due to distance and the signal attenuation due to vegetation, the intensity of the electrical field of direct path $\left(E_{d}\right)$ can be expressed as:

$$
E_{d}=E_{0} \cdot \frac{e^{-\alpha . d}}{d}
$$




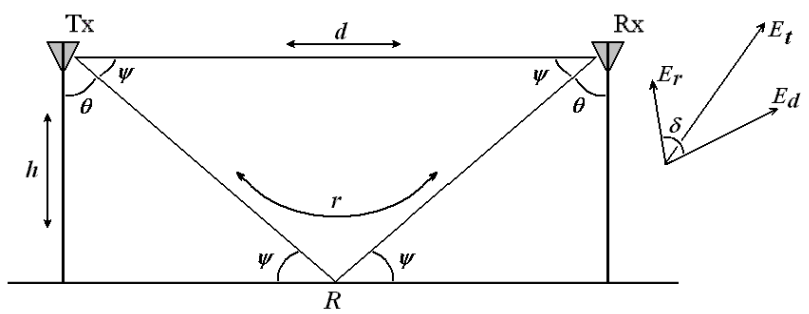

Figure 1: Graphical representation of propagation in two paths

and the intensity of the electrical field of reflected path $\left(E_{r}\right)$ as:

$$
E_{r}=E_{0} \cdot \frac{e^{-\alpha . r}}{r} \cdot R\left(\psi, \in_{s}, p\right) \cdot D(\theta)
$$

where $E_{0}$ is a value of reference for the electrical field intensity, measured for 1 meter distance and free space condition ( $\alpha=0) . D(\theta)$ is antenna directivity and $R\left(\psi, \in_{s}, p\right)$ is soil reflectivity, which is a function of the angle of incidence $(\psi)$, dielectric constant of soil $\left(\in_{s}\right)$, and the electrical field polarity ( $p$ - horizontal or vertical).

In this work only vertical polarization was used. Soil reflectivity for vertical polarization $\left(R_{v}\right)$ is calculated according to equations (8) and (9) (Meissner \& Wentz, 2004):

$$
\begin{aligned}
& R_{v}=\frac{\operatorname{sen}(\psi)-Z}{\operatorname{sen}(\psi)+Z} ; \\
& Z=\frac{\sqrt{\epsilon_{s}-\cos ^{2}(\psi)}}{\epsilon_{s}}
\end{aligned}
$$

The receiver senses an electromagnetic power that is a square function of the electric field (Ulaby et al., 1981):

$$
P=\frac{1}{2} \cdot E \cdot H \cdot A=\frac{E^{2}}{2 \eta} \cdot A
$$

where $E$ and $H$ represent electric and magnetic fields, respectively; $A$ represents the effective aperture of the receiver antenna; and $\eta$ is the intrinsic resistance of the medium.

Therefore, according to the model proposed in this work the total received power $\left(P_{R t}\right)$ will be a composition of direct path power $\left(P_{d}\right)$ and reflected path power $\left(P_{r}\right)$ :

$$
E_{t}^{2}=E_{d}^{2}+E_{r}^{2}+2 \cdot E_{d} \cdot E_{r} \cdot \cos (\delta)
$$

$$
P_{R t}=P_{d}+P_{r}+2 \cdot \sqrt{P_{d} \cdot P_{r}} \cdot \cos (\delta)
$$

$P_{R t}$ can be related to a reference value of power $\left(P_{R 0}\right)$, mesured at 1 meter of distance and in free space. This relation is a dimensionless function $Q\left(d, h, \lambda, \alpha, \in_{s}\right)$ that depends on the variables distance between radios $(d)$, radios height from soil surface $(h)$, soil dielectric constant $\left(\epsilon_{s}\right)$, wave length $(\lambda)$ and attenuation factor $(\alpha)$ :

$$
\frac{P_{R t}}{P_{R 0}}=Q\left(d, h, \in_{s}, \alpha, \lambda\right)
$$

$$
\begin{aligned}
& Q\left(d, h, \in_{s}, \alpha, \lambda\right)=\frac{e^{-2 \cdot \alpha \cdot d}}{d^{2}}+ \\
& \quad+\frac{e^{-2 \cdot \alpha \cdot r}}{r^{2}} \cdot D^{2}(d, h) \cdot R_{v}^{2}\left(d, h, \in_{s}\right)+ \\
& \quad+\frac{2 \cdot e^{-\alpha \cdot(r+d)}}{r \cdot d} \cdot D(d, h) \cdot R_{v}\left(d, h, \in_{s}\right) \cdot \cos (\delta)
\end{aligned}
$$

where distance $r$ is calculated as:

$$
r=\sqrt{d^{2}+4 h^{2}}
$$

The vegetation influence is represented by the absorption factor $(\alpha)$, that is strongly affected by vegetation water content. If wave length $(\lambda)$ and reference power $\left(P_{R 0}\right)$ are known, $\alpha$ can be determined since the variables $P_{R t}, \in_{s}, d$ and $h$, are measured.

Figure 2 is a graph of the function relating Pass Loss $\left(P_{R}-P_{T}\right)$ to the distance of the electromagnetic signal propagation considering 3 different conditions. The dash-dot line refers to propagation in line of sight (LOS) only. Continuous lines represent two path propagation models, one for the radios placed at 1 meter from soil surface and the other for the radios placed at 1.5 meter high. The following parameters were used in these models: $P_{T}=0 \mathrm{dBm}, f=916 \mathrm{MHz}$ $(\lambda=0.33 \mathrm{~m})$, and $\alpha=0.15$. The value 0.15 for $\alpha$ is in accordance to previous works (Jackson \& Schmugge, 1991; Wgneron et al., 2004). The discrete points presented in figure 2 refer to experimental results obtained from measurements in corn fields, where sensor nodes were placed at $1.5 \mathrm{~m}(*)$ and at $1.0 \mathrm{~m}$ (o) from soil surface. Measurements were taken on different days and in different fields. In all of them plants were 2 meters high and well irrigated.

In a practical sense, when the difference in the propagation distances is small ( $r \cong d)$, or when height is small compared to distance, $h / d \rightarrow 0$, the differences between the 3 exponentials in equation (14) can be disregarded. Therefore, one can consider that: 


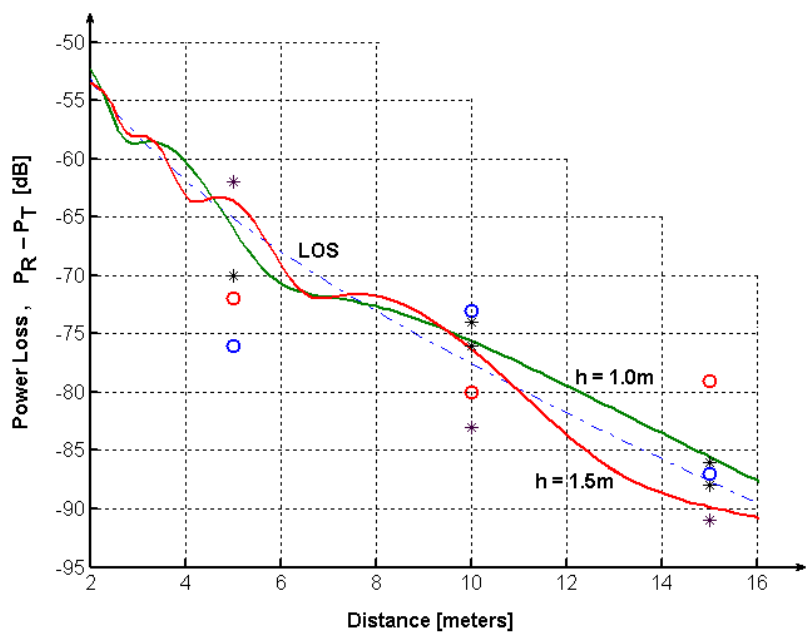

Figure 2: Attenuation due to vegetation. Continuous lines represent models $(\alpha=0.15)$. Discrete points are measured values $(\mathrm{o}=$ nodes at $1.0 \mathrm{~m}$ high; $*=$ nodes at $1.5 \mathrm{~m}$ high $)$

$$
e^{-\alpha \cdot r} \cong e^{-\alpha \cdot d}
$$

This promotes a simplification in the calculation of absorption factor $(\alpha)$ and clarifies the linear relation between this parameter and power attenuation of radio signals (in $\mathrm{dB}$ ).

As an example, if $d=10.0 \mathrm{~m}$ and $h=1.0 \mathrm{~m}$, the distance in reflected path is $r=10.2 \mathrm{~m}$ and the soil reflectance is limited, $|R|<0.5$. Considering the approximation $e^{-\alpha . r}=e^{-\alpha . d}$ results a deviation less than $10 \%$ in parameter $\alpha$ calculation, which means a deviation smaller than $10 \%$ in the final estimation of plant gravimetric water content $\left(m_{g}\right)$.

\section{ATTENUATION DUE TO VEGETATION}

Many models of electromagnetic wave propagation in vegetable medium were developed in past decades. In these models any material placed in the wave propagation path is considered as a dielectric. This dielectric modifies wave characteristics and causes deviation (diffraction) or absorption (attenuation) of electromagnetic energy of the waves (Beckwith et al., 2004; Giacomin \& Vasconcelos, 2006a; Willing et al., 2005). The most popular models are the half-space random medium sacatter model (Fung \& Fung, 1977), the water cloud model (Attema \& Ulaby, 1978), and MIMICS (Michigan Microwave Canopy Scattering), proposed by Ulaby (Maity et al., 2004).

In remote sensing of vegetable areas, the microwave signals are used to estimate soil and plant moisture. This is made by sensors embedded in artificial satellites or aircrafts as well as sensors installed in a structure attached to the Earth sur- face. Microwave is preferable over infra-red and light signals in soil and plant moisture estimation as it covers an electromagnetic wave band that suffers great attenuation by bound water (Jackson \& Schmugge, 1991). Because of that, microwave remote sensing is applicable in vegetation biomass and leaf area index (LAI) estimation (Maity et al., 2004).

After Fung \& Fung (1977) and Attema \& Ulaby (1978), Jackson \& O'Neil (1990) proposed a simple model that relates vegetation water content to electromagnetic wave power loss. According to Jackson \& O'Neil (1990), attenuation on microwaves that pass through vegetation is a decreasing exponential function calculated with a product of two terms: a parameter $b$, that depends on vegetation species, and the vegetation water content $(W)$ :

$$
\frac{P_{R}}{P_{T}}=e^{-b \cdot W}
$$

$W$ is the water content of vegetation canopy (the part of vegetation populated by leaves) by area unit, and it is calculated as a product of gravimetric moisture of plants $\left(m_{g}\right)$, the distance $(d)$ that microwave penetrates vegetation and the volume fraction of the canopy filled with vegetation $\left(V_{p} / V\right)$, as stated in equation (17). $V_{p}$ is plant volume and $V$ is total canopy volume.

$$
W=m_{g} \cdot d \cdot \frac{V_{p}}{V}\left(\mathrm{~kg} / \mathrm{m}^{2}\right)
$$

Schmugge \& Jackson (1992) studied the adaptation of two models for parameter $b$ : a linear model and a refractive model, also denominated square root model. Refractive model is appropriate for propagation in vegetation with low contribution of stems (ex. soybean), but it is not a good choice when the electric field is aligned with the vegetation stems. The authors concluded that for signal of large wavelengths $(\lambda>5 \mathrm{~cm})$, the value of parameter $b$ is almost constant in respect to frequency and plant water content. This model is denominated here as "Jackson"s model".

Wigneron et al. (2004) presented a study on parameter $b$ of Jackson's model, and gave the following conclusions:

- The main determinant of $b$ values are crop type: the average values for soybean canopies are 0.20-0.30, and for corn canopies are $0.15-0.20$;

- The dependence of parameter $b$ on polarization is significant over crops with strong contribution of stems, as wheat and corn;

- Excluding the early phase of the vegetation development, parameter $b$ is almost constant over the time. 
Jackson's model is adopted in this work for the microwave propagation that occur between two radio stations located close to soil surface, positioned at same height and separated by a distance $(d)$ from each other. Under these conditions, the microwaves propagate only inside vegetation canopy, which acts as a dielectric. As a consequence, one can relate the attenuation factor $\alpha$ to the vegetation water content $(W)$ and to plant gravimetric moisture $\left(m_{g}\right)$ :

$$
2 \cdot \alpha \cdot d=b \cdot W=b \cdot m_{g} \cdot d \cdot \frac{V_{p}}{V}
$$

or

$$
m_{g}=\frac{2 \cdot \alpha}{b \cdot \frac{V_{p}}{V}}
$$

Then, since the value of parameter $b$ is determined and considered constant, and volumetric fraction of the canopy $\left(V_{p} / V\right)$ is constant, measuring absorption factor $(\alpha)$ is enough to achieve plant water content $\left(m_{g}\right)$.

We propose that $\alpha$ is calculated as a function of the power attenuation of the electromagnetic signal from the communications between WSN sensor nodes, which were deployed in an agricultural crop field. This function is described in the next section.

\section{CALCULATING ABSORPTION FACTOR}

According to the theory presented in preceding section, the absorption factor $(\alpha)$ relative to vegetation can be considered as a function of the other parameters present in equation (14) and can be estimated from the measurement of the total received power $\left(P_{R t}\right)$ in the communication of pairs of WSN nodes. If distance $d$ and height $h$ are known, distance $r$, the angles $\theta$ and $\psi$, and the antenna directivity $(D)$ can be calculated. If wave length $(\lambda)$ is known, the difference in phase $(\delta)$ of electric fields is calculated. Dielectric constant of soil $\left(\in_{s}\right)$ must be measured in order to calculate soil reflectivity $(R)$. As soon as the total received power $\left(P_{R t}\right)$ is measured and the reference power $\left(P_{R 0}\right)$ is known, only absorption factor $(\alpha)$ remains to be determined. Since $d, h, r, \lambda, D, P_{R 0}, \theta$ and $\psi$, are permanent, it is only needed to measure $R$ (or $\in_{s}$ ) and $\left(P_{R t}\right)$ to estimate $\alpha$. The value of $\in_{s}$ (and $R$ ) changes with soil moisture.

Using the function $Q\left(d, h, \in_{s}, \lambda, \alpha\right)$, one can verify that it is not possible to obtain the absorption factor $(\alpha)$ directily. A numeric iteractive method have to be used. The first choice is the Newton's method. Its convergence is easely demonstrated to parameter $\alpha$ calculation using function $Q$. Another sucessive approximation method is obtained when some algebraic manipulations are made on function $Q$. This is presented in equations (20) to (22).

$$
\begin{aligned}
Q=e^{-2 \cdot \alpha \cdot d} \cdot\left[\frac{1}{d^{2}}+\frac{e^{-2 \cdot \alpha \cdot(r-d)}}{r^{2}} \cdot D^{2} \cdot R_{v}^{2}+\right. \\
\left.\quad+2 \cdot \frac{e^{-\alpha \cdot(r-d)}}{r \cdot d} \cdot D \cdot R_{v} \cdot \cos (\delta)\right]=\frac{P_{R t}}{P_{R 0}}
\end{aligned}
$$

$$
\begin{aligned}
& e^{-2 \cdot d \cdot \alpha(k+1)} \cdot\left[\frac{1}{d^{2}}+\frac{e^{-2 \cdot(r-d) \cdot \alpha(k)}}{r^{2}} \cdot D^{2} \cdot R_{v}^{2}+\right. \\
& \left.+2 \cdot \frac{e^{-(r-d) \cdot \alpha(k)}}{r \cdot d} \cdot D \cdot R_{v} \cdot \cos (\delta)\right]=\frac{P_{R t}}{P_{R 0}}
\end{aligned}
$$

$$
\begin{gathered}
\alpha(k+1)=\frac{1}{2 d} \cdot \ln \left(\frac { P _ { R 0 } } { P _ { R t } } \cdot \left[\frac{1}{d^{2}}+\frac{e^{-2 \cdot(r-d) \cdot \alpha(k)}}{r^{2}} \cdot D^{2} \cdot R_{v}^{2}\right.\right. \\
\left.\left.+2 \cdot \frac{e^{-(r-d) \cdot \alpha(k)}}{r \cdot d} \cdot D \cdot R_{v} \cdot \cos (\delta)\right]\right)
\end{gathered}
$$

This method, here denominated "logarithm method", demands less calculations than Newton's method, as the derivative of function $Q$ is not needed. This makes "logarithm method" a good choice when the calculations are made by sensor nodes. In sensor nodes, less calculations translate to battery save and longer time of operation. Besides that, this method promotes a faster convergence than Newton's method, in some cases. While Newton's method makes a linear approach to the final value, the logarithm method promotes exponential approach, when the estimated value is distant from the correct one.

The series obtained with the logarithm method is convergent and approximates the series of Newton's method when $\alpha(k)$ is close to the correct $\alpha$ value, or when $Q(\alpha(k))$ is close to $P_{R t} / P_{R 0}$.

Figure 3 presents a sequence of iterations in the calculation of factor $\alpha$, using the logarithm method, observing the condition $d \gg h(r \cong d)$ and considering the following parameters:

$\lambda=0.33 \mathrm{~m}(f=916 \mathrm{MHz}) ; l$ (Antenna length) $=\lambda / 4$; antenna dipole; $\epsilon_{s}=16.1-\mathrm{j} 3.4$ (taken from LeVine \& Karam (1996)); $\alpha=0.150$. It was established a stop condition based on the modulus of the relative received power error $\left(|\mathrm{e}|<1 \cdot 10^{-8}\right)$ :

$$
e=\frac{P_{R}^{*}-P_{\text {Rest }}}{P_{R}^{*}}
$$

where $P_{R}^{*}$ is the value obtained when the correct value of $\alpha$ is used, and $P_{\text {Rest }}$ is calculated using the estimated value $\alpha(k)$.

The final value of $\alpha$ was obtained in 4 iterative steps, $\alpha(4)=\alpha=0.150$, and the sequence of relative errors was: 


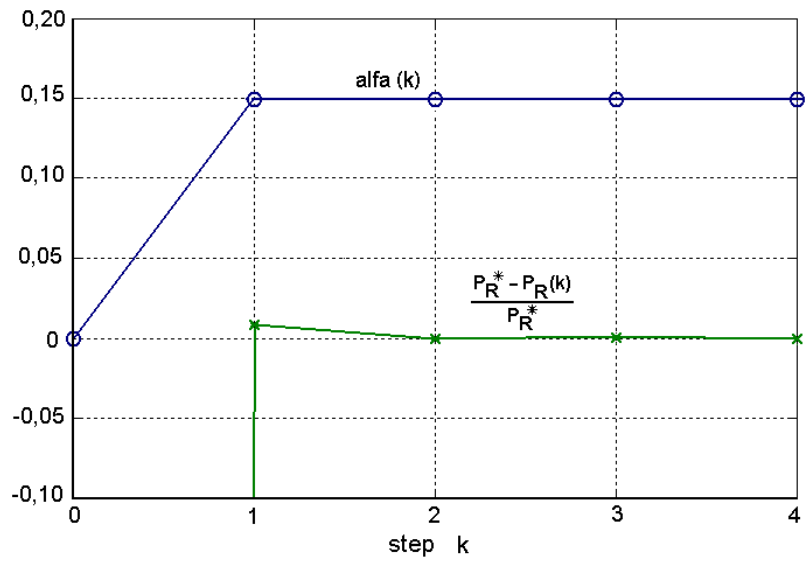

Figure 3: Iteractive calculus of $\alpha . d=15 \mathrm{~m} ; h=1.0 \mathrm{~m}$; $D=0.99 ; R_{v}=-0.29 ; \cos (\delta)=-0.84$

$e=\left[-89.7 ; 8.08 \cdot 10^{-3} ; \quad-14.5 \cdot 10^{-6} ; 25.8 \cdot 10^{-9}\right.$; $\left.-46.1 \cdot 10^{-12}\right]$.

An analysis of the parameter $\alpha$ sensibility, on that series calculation, related to the other variables, indicate that greater distances $(d$ and $r)$ result in best estimates for absorption factor. Considering that the sensor nodes height $(h)$ is limited by plant height ( 2 meters for corn), increasing distances force the ratio $h / d \rightarrow 0$ and $\left|E_{d}\right| \cong\left|E_{r}\right|$. In order to inprove convergence of the $\alpha(\mathrm{k})$ series, care must be taken in deploing nodes in places that make the factor $\cos (\delta)$ approximates -1 . This care lead to a constructive $E_{d}$ and $E_{r}$ fields interaction, improving the sensibility of RF power loss to factor $\alpha$. In order to achieve this condition, the difference between distances $d$ and $r$ must be an odd number of halves of wave length, as indicated in equations (24) and (25):

$$
\cos (\delta)=\cos \left(\frac{2 \cdot \pi}{\lambda} \cdot(r-d)\right) \cong-1
$$

$$
\frac{2 \cdot \pi}{\lambda} \cdot(r-d) \cong \pi ; \quad(r-d) \cong n \cdot \frac{\lambda}{2} ; \quad n=1,3,5 \ldots
$$

\section{METODOLOGY}

In order to perform the measurements of power attenuation of the WSN radio signals communication, to estimate vegetation water content, some care must be taken. The sensor nodes must be deployed at regular distances and height. It is recommended that a triangular distribution is used, resulting in equal distances between neighbor nodes. In this way, all calculations for signal attenuation will be related to the same distances and height, reducing computational efforts. As consequence, all values of directivity $(D)$ and $\cos (\delta)$ will be common to all pairs of nodes. Soil reflection indexes $(R)$ will be uniform, as the soil moisture in the region of measurement is uniform. Short distances, less than 5 meters, must be avoided in order to reduce power loss variations due to uncertainties in distance (position), as viewed in figure 2. Besides, as $h / d$ rate increases, the directivity model became less accurate to real values (measurements were made to confirm this fact). Height $(h)$ and distance $(d)$ values must be chosen in order to favor positive interactions between direct path $\left(E_{d}\right)$ and reflected path $\left(E_{r}\right)$ electric fields. This make higher the sensibility of total received power to variations in absorption factor $(\alpha)$, and consequently to the variations in plant water content $\left(m_{g}\right)$. The installation of the wireless sensor network in the vegetal medium must be made in such a mode that neighbor nodes do not lay in the same row, or there will not be plants in the way of radio wave propagation. A hypothetical nodes distribution example in a corn field is presented schematically in figure 4. Receptors and transmitters must be calibrated. It is recommended to adjust transmitters to the same power, typically $0 \mathrm{dBm}$, in order to reduce computational effort.

As represented in figure 4, plant distribution along different propagation paths is not uniform, and then different power losses will be observed for different pair of nodes, even though the water content is the same for all plants in a region.

Therefore, it is necessary to compute an average value from several power loss measurements, taken in several distinct propagation paths, in order to obtain a representative value of the absorption factor $(\alpha)$ and plant water content $\left(m_{g}\right)$ of the vegetation present in that region of the field. This average value will be used by an agriculturist to make decisions about the crop field management. As an example, it can be computed the average of power loss measured by the three nodes in the three corners of a triangle, considering the three paths in triangle sides. The greater the number of power losses measurement in different propagation paths the closer is the

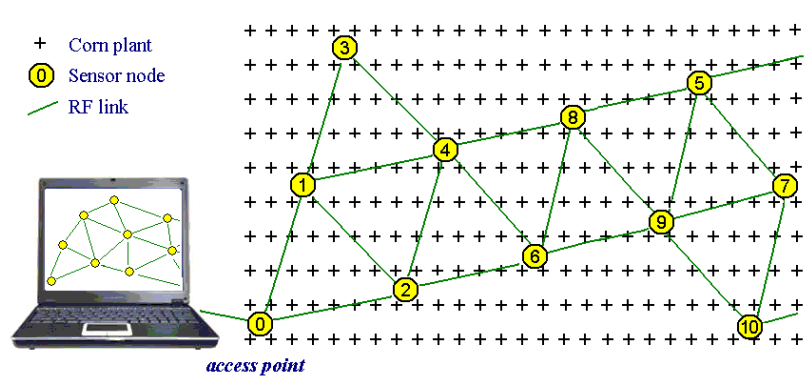

Figure 4: Diagram of an array of sensor nodes in corn field disposed in triangular shape. The three nodes closer to the computer represent the sensor nodes used in this work. 
obtained average value to a representative value of the plant population in a given region. Then more confident will be the agriculturist in his management decisions. This fact is according to central limit theorem (McClave, 2000).

A series of received signal strength (RSS) measurements must be conducted in each propagation path, in order to obtain a representative value of attenuation in that path (Giacomin \& Vasconcelos, 2006b). It is justified because RSS measured values fluctuates around an average value with gaussian distribution, as seen in figure 5. It is suggested series of at least 50 measurements. The variations in RSS values are due not only to the characteristics of the equipment but also to dynamic characteristics of the plants, which are in constant movement caused by wind.

\section{EXPERIMENTAL RESULTS}

In this work, it was used the received signal strength measurements taken from the nodes of a wireless sensor network in order to estimate the plant water content of a corn crop field. In order to identify exclusively the influence of vegetation in the radio wave power loss, two measurement sequences were performed: the first one was conducted under free condition (without vegetation) and the second one was carried out with the WSN placed inside a corn field. Both experiments were conducted with sensor node equidistantly deployed and all antennas at vertical position. In each sequence, 100 RSS measurements were taken for each sensor node pair (100 values for the communication between node 1 and node 2, 100 values for node 2 and node 0 , etc).

Figure 5 presents an example of frequency distributions of RSS taken from a pair of sensor nodes, for two distinct conditions. The first measurement sequence was executed in a free place (without vegetation) and the second one was conducted in a corn field. All other parameters $\left(d, h, P_{T}\right.$, etc) were set as constants. One can observe that vegetation caused a small increase in the dispersion of measured values of total received power $\left(P_{R t}\right)$, besides it has caused an increment in mean value.

The WSN used in these experiments was composed by MICA2 (Crossbow, 2005) sensor node platforms, with transmitters adjusted to $0 \mathrm{dBm}(1 \mathrm{~mW})$. These sensor nodes employ radios CC1000 (Chipcon, 2002), which operate in 916 MHz ISM (license free) band. It was taken the measurements of RSS at all communication paths, for all pair of nodes. CC1000 measures and informs received power strength as RSSI (Received Signal Strength Information), which is an analog voltage $\left(V_{R S S I}\right)$ related to received power as:

$$
P_{R}=-50 \cdot V_{R S S I}-45.5[\mathrm{dBm}]
$$

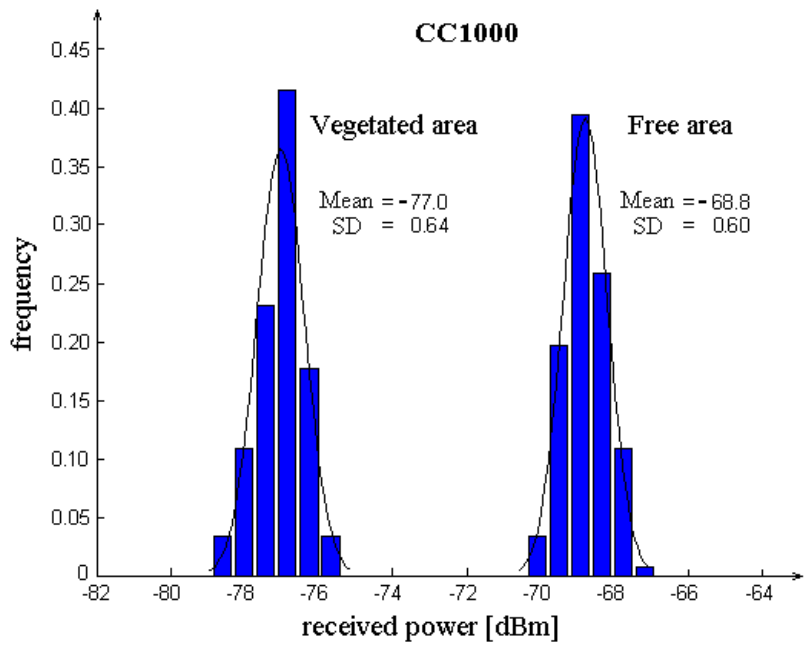

Figure 5: Normal distribution of $P_{R t}$ measured values under two distinct conditions: in free path and in a corn field.

$V_{R S S I}$ is converted for a binary value by a 10 bit $\mathrm{ADC}$ present in the microcontroller Atmega 128L (Atmel, 2004), which is a component of MICA2. The binary indication of RSSI is related to $V_{R S S I}$ as stated in equation (27):

$$
V_{R S S I}=\frac{R S S I_{-} D I G \cdot V_{B A T}}{1024}
$$

where $R S S I-D I G$ is the 10 bit binary correspondent to $V_{R S S I}$ and $V_{B A T}$ is the node battery voltage (about $3.0 \mathrm{~V}$ ).

\subsection{Linearity between power loss and vegetation water content}

This experiment was planed with the objective of verifying the linear relation between electromagnetic signal attenuation and the amount of water present in vegetation in the propagation path of WSN radio communications. So, two sets of measurements were performed, as stated in methodology (section 6). One set of measurement was conducted in a corn crop field, which was in the second half of its growing period (100 days after seeding), that corresponds to its reproductive stage. The average corn height was about 2 meters.

In each measurement set was performed three measurement sequences with sensor nodes deployed equidistantly in a triangular shape, and at equal height from soil surface. Only the distances between nodes were made different each sequence. The distance in the first sequence was 5 meters, in the second sequence it was 10 meters, and 15 meters for the third sequence. All the nodes were 1 meter high from soil surface and all antennas at vertical position. It was taken 100 RSS measurements each sequence for each propagation path. 


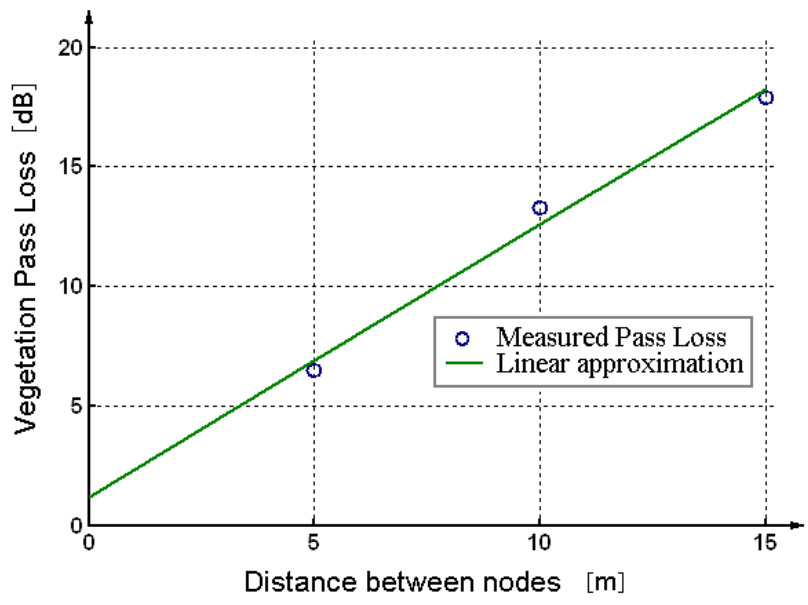

Figure 6: Attenuation caused by vegetation as a function of distance between sensor nodes of a WSN

The same procedure was taken in a field without vegetation, close to corn field. All measurements was taken in an one hour interval, so that changes in environmental conditions were minimal as well as the vegetation characteristics.

Table 1 presents the average attenuation values of the communication signals $\left(P L=P_{T}-P_{R}\right)$ obtained from 100 measurement taken in each pair of nodes communication links. The general average (for all communication links) and the highest and the least averages (of particular links) are presented. One can verify that in a free place, Pass Loss $(P L)$ varied about $6 \mathrm{~dB}$, while in the vegetated place variations in $P L$ were higher than $20 \mathrm{~dB}$.

Table 1: $P L$ - Power Loss in RF propagation paths

\begin{tabular}{|c|c|c|c|}
\hline \multicolumn{4}{|c|}{$P_{T}-P_{R}$} \\
\hline Distance & $\begin{array}{c}\text { Free path } \\
\text { mean value }(\text { min. } \sim \text { max.) }\end{array}$ & $\begin{array}{l}\text { Vegetated path } \\
\text { mean value }(\text { min. } \sim \text { max.) }\end{array}$ & Difference \\
\hline $5.0 \mathrm{~m}$ & $67.1 \mathrm{~dB}(63.9 \sim 70.1)$ & $75.9 \mathrm{~dB}(66.1 \sim 89.5)$ & $8.7 \mathrm{~dB}$ \\
\hline $10.0 \mathrm{~m}$ & $65.9 \mathrm{~dB}(64.3 \sim 67.3)$ & $81.5 \mathrm{~dB}(73.6 \sim 95.6)$ & $15.6 \mathrm{~dB}$ \\
\hline $15.0 \mathrm{~m}$ & $69.0 \mathrm{~dB}(68.2 \sim 70.3)$ & $90.6 \mathrm{~dB}(84.6 \sim 97.8)$ & $21.6 \mathrm{~dB}$ \\
\hline
\end{tabular}

The fourth column of table 1 points the difference in $P L$ due to presence of vegetation, and this difference increases when distance increases, proportionally. These data are visualized in figure 6 , where circles refer to measured data and the straight line is a linear approximation. Figure 6 shows that power attenuation in the communication signals caused by vegetation is a linear function of the amount of plants in the path of propagation, then is a function of the amount of water in the path (the main component of plants is water).

\subsection{Estimation of vegetation water con- tent}

The second experiment was conducted in a corn crop field, at Federal University of Lavras (UFLA - Universidade Federal de Lavras), state of Minas Gerais, Brazil, in March/2006. Following the methodology proposed in section 6 , a WSN was deployed in the corn field, and the sensor nodes were placed at $1.5 \mathrm{~m}$ high and at $10 \mathrm{~m}$ distant from each other. The vegetation was composed by 2 meter high plants and 8 plants per square meter. The transmitters were adjusted to $P_{T}=0 \mathrm{dBm}$. It was obtained $P_{R v}=-80.6 \mathrm{dBm}$ as average value of received power signal as the measurements were taken in presence of vegetation (index $v$ extends for vegetation). The average value obtained from measurements conducted in free path (without vegetation) was $P_{R f}=-69.7$ $\mathrm{dBm}$ (index $f$ extends for free path). Soil moisture was about $10 \%(\theta v \cong 10 \%)$, resulting in a estimated reflectivity of 0.1 $(R \cong 0.1)$. The distance of propagation in the reflected path was $r=10.44 \mathrm{~m}$, resulting that $\cos (\delta)=-0.5$.

Applying equations (13) and (14), and taken the received power in free path $\left(P_{R f}\right)$ it is possible to calculate the reference power $\left(P_{R 0}\right)$. Here $\alpha=0$.

$$
\frac{P_{R f}}{P_{R 0}}=\frac{1}{d^{2}}+\frac{1}{r^{2}} \cdot D^{2} \cdot R_{v}^{2}+2 \cdot \frac{1}{r \cdot d} \cdot D \cdot R_{v} \cdot \cos (\delta)
$$

This leads to $P_{R 0}=8.86 \times 10^{-6} \mathrm{~mW}=-50.5 \mathrm{dBm}$.

Applying the same equations and the value of received power in vegetated path $\left(P_{R v}\right)$, it is obtained an expression to calculate iteratively the value of variable $\alpha$ :

$\frac{P_{R v}}{P_{R 0}}=\frac{e^{-2 . \alpha . d}}{d^{2}}+\frac{e^{-2 . \alpha . r}}{r^{2}} \cdot D^{2} R_{v}^{2}+\frac{2 . e^{-\alpha \cdot(d+r)}}{r \cdot d} \cdot D \cdot R_{v} \cdot \cos (\delta)$

Using the iterative method presented in section 5 , it is achieved an estimated value for the absorption factor electromagnetic waves by vegetation: $\alpha=0.123$. This value is in agreement to the values calculated using the models proposed by Schmugge \& Jackson (1992).

As pointed in section 3, the calculation of parameter $\alpha$ should be simplified if all exponential functions were considered as being the same value. Then it is written:

$$
\frac{P_{R v}}{P_{R 0}}=e^{-2 . \alpha . d} \cdot\left[\frac{1}{d^{2}}+\frac{1}{r^{2}} \cdot D^{2} R_{v}^{2}+\frac{2}{r \cdot d} \cdot D \cdot R_{v} \cdot \cos (\delta)\right]
$$




$$
\frac{P_{R v}}{P_{R f}}=e^{-2 . \alpha . d}
$$

and finally:

$$
4.34 \cdot 2 \cdot \alpha \cdot d=P_{R v}-P_{R f} \quad[d B]
$$

Thus, the absorption factor is easily computed:

$$
\alpha=\frac{-69.7-(-80.6)}{4.34 \cdot 2 \cdot 10}=0.126
$$

Using equation (18), and the value of parameter $b(b=$ 0.15 ) indicated by Wigneron et al. (2004) and Jackson \& Schmugge (1991), the vegetation water content can be estimated:

$$
\begin{gathered}
2 \cdot \alpha=b \cdot m_{g} \cdot \frac{V_{p}}{V}=b \cdot m_{g(\text { canopy })} \\
m_{g(\text { canopy })}=\frac{2 \cdot \alpha}{b}=1.64 \quad\left[\mathrm{~kg} / \mathrm{m}^{3}\right]
\end{gathered}
$$

Samples of corn plants were caught in this experiment, and their gravimetric moisture was measured, employing a gravimetric method. The samples were weighted after catching and after drying in oven. The difference in mass was attributed to water content $\left(\mathrm{M}_{\text {water }}=0.4 \mathrm{~kg}\right)$. The mean gravimetric moisture of the plants was $\mathrm{m}_{g}=80 \%$ with standard deviation $\mathrm{SD}<4 \%$. Only the plants, without earns, were weighted.

Considering a mean of 8 plants per square meter, and an average plant height of 2 meters, the vegetation water content was calculated:

$$
m_{g(\text { canopy })}=\frac{0.4 \cdot 8}{2}=1.6 \quad\left[\mathrm{~kg} / \mathrm{m}^{3}\right]
$$

This value agrees with the estimated value and this result indicate that the value of parameter $b=0.15$ is representative for the corn crop used in this experiment.

Figure 7 presents the values of attenuation measured in 6 links between 3 sensor nodes $(0,1,2)$ placed in the corn field at equal distances of $10 \mathrm{~m}$. Attenuations in the path of communications between nodes 1 and 2 (links 1_2 and 2_1) are close to the mean value (M). Attenuations in the path of nodes 0 and 1 were stronger than the others, while in the path between nodes 0 and 2 the attenuations were weaker. These differences are attributed to the non uniform distribution of plants in the field.

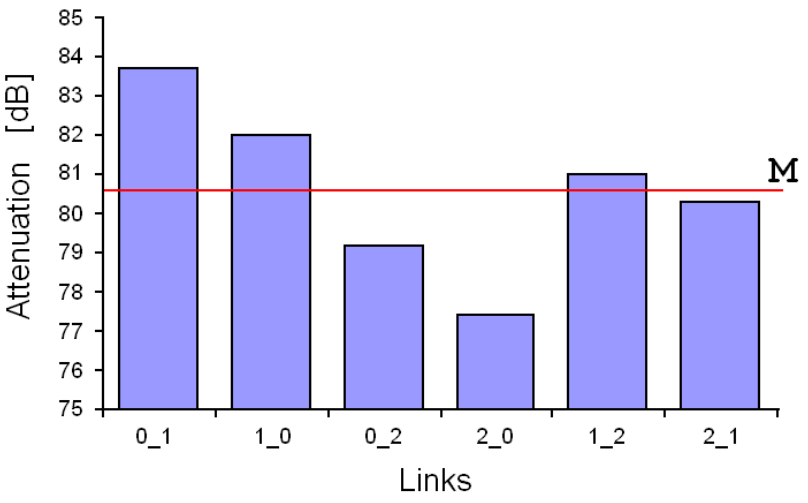

Figure 7: Attenuations measured in 6 links between nodes 0 , 1 and 2, placed in the corn field, distant $10 \mathrm{~m}$ from each other

\section{CONCLUSIONS}

It was presented a distributed measurement system of vegetal crop water content which uses the radio communication signals of a wireless sensor network. It was explained the importance of distributed measurement for the collection of information from the vegetation of crop fields in order to support agriculturist decisions. A model of electromagnetic wave propagation considering multipath was proposed in order to obtain a function that is useful to estimate the absorption factor $(\alpha)$ of vegetation. Due to the complexity of the model, the parameter $\alpha$ must be calculated in a recursive mode. The multipath propagation model showed to be appropriated for the data measured in corn fields. Experimental results (figure 6) demonstrated the linear relation between the attenuation caused by vegetation and the amount of vegetation (consequently water) present in the propagation way of a WSN communication signal.

The value of parameter $\alpha$ obtained with the method proposed here for a corn crop field complies with previous works (Schmugge \& Jackson, 1992). The water content of the vegetation canopy estimated by the WSN signals was compared to the value obtained by the standard gravimetric method. The result demonstrated the viability in employing the method proposed here.

Figure 7 shows that the attenuation of communication signals between a pair of sensor nodes inside a corn field may vary strongly (more than $6 \mathrm{~dB}$ ) depending on the way of radio wave propagation. This is due to the non uniform distribution of plants in the field. The technique of distributed measurement is then suggested. The average value of several measurements taken in a wide spread form in the field results in a more useful value of vegetation water content.

The method proposed here can be applied to other crops, like soybeans and wheat, since parameter $b$ is known. The mea- 
surement of vegetation water content with WSN signals is attractive because it does not demand additional sensors to obtain the desired information, as the WSN itself is used as a sensor. Moreover, WSN is able to collect data from the field even during the night and in small intervals, what is not possible with satellite remote sensing.

\section{REFERENCES}

Atmel Corporation (2004); Atmega128L - 8-bit AVR Microcontroller with $128 \mathrm{~K}$ Bytes - In-System Programmable Flash. Manual do fabricante, 328 p. Disponível em <www.atmel.com>. Acesso em 12/07/05

Adamchuk, V. I., Hummel, J. W., Morgan, M. T., Upadhyaya, S. K. (2004). On-the-go soil sensors for precision agriculture. Computers and Electronics in Agriculture, vol. 44, pp. 71-91

Attema, E. P. W. \& Ulaby, F. T. (1978). Vegetation Modeled as a Water Cloud. Radio Science, vol. 13, pp. 357-364

Bakhsh, A., Jaynes, D. B., Colvin, T. S., Kanwar, R. S. (2000). Spatio-Temporal Analysis of Yield Variability for a Corn-soybeam Field in Iowa. Transactions of the $A S A E$, vol. 43, pp. 31-38.

Beckwith, R., Teibel, D., Bowen, P. (2004). Report from the Field: Results from an Agricultural Wireless Sensor Network. Proceedings of the 29th Annual IEEE International Conference on Local Computer Networks (LCN’04), Tampa, USA, pp. 471-478.

Bulusu, N., Heidemann, J., Estrin, D. (2004). SelfConfiguring Localization Systems: Design and Experimental Evaluation. ACM Transactions on Embeded Computing Systems, vol. 3, $\mathrm{n}^{o}$ 1, pp. 24-60

Chipcon AS (2002). CC1000 - Single Chip Very Low Power RF Transceiver (rev. 2.1). Manual do fabricante, $48 \mathrm{p}$. Disponível em: <http://www.chipcon.com>. Accesso em: 12/07/05.

Crossbow Technology, Inc. (2005). Wireless Sensor Networks. Manual do fabricante, 30 p. Disponível em: <http://www.xbow.com>. Acesso em: 12/07/05

Fung, A. K. \& Fung, H.S. (1977). Application of FirstOrder Renormalization Method to Scattering from a Vegetation-Like Half-Space; IEEE Transactions on Geoscience Electronics, vol. GE15, pp. 189-195

Giacomin, J.C. \& Vasconcelos, F.H. (2006a). Wireless Sensor Network as a Measurement Tool in Precision Agriculture. in XVIII IMEKO WORLD CONGRESS Metrology for a Sustainable Development, September, 17 - 22, Rio de Janeiro, Brazil
Giacomin, J.C. \& Vasconcelos, F.H. (2006b). Qualidade da Medição de Intensidade de Sinal nas Comunicações de uma Rede de Sensores Sem Fios: uma Abordagem da Camada Física. InfoComp, vol. 5, $\mathrm{n}^{\circ} 2$, pp. 83-92

Hatfield, J. L. (2000). Precision Agriculture and Environmental Quality: Challenges for Research and Educational. Agricultural Research Service, USDA, Ames, Iowa. Obtained in <http://www.arborday.org/PROGRAMS/ papers/PrecisionAg.html>. Access: 23/Jan/2005

Heidemann, J. \& Govindan, R. (2004). Embedded Sensor Networks. In Handbook of Networked and Embedded Control Systems. D. Hristu-Varsakelis and W.S. Levine, editors. Springer Verlag, 18p.

Hornbuckle, B. K. (2003). Radiometric Sensitivity to Soil Moisture Relative to Vegetation Canopy Anisotropy, Canopy Temperature, and CanopyWater Content at 1.4 $\mathrm{GHz} ; P h D$ tesis on Electrical Engineering and Atmospheric, Oceanic \& Space Sciences. University of Michgan, $135 \mathrm{p}$.

Jackson, T.J. \& O’Neil, P.E. (1990). Attenuation of Soil Microwave Emission by Corn and Soybeans at 1.4 and 5 $\mathrm{GHz}$; IEEE Transactions on Geoscience and Remote Sensing, vol. 28, $\mathrm{n}^{\circ} 5$, pp.978-980

Jackson, T.J. \& Schmugge, T.J. (1991). Vegetation Effects on the Microwave Emissions of Soils. Remote Sensing Environment, vol. 36, pp. 203-212

Leon, C. T., Shaw, D. R., Cox, M. S., Abshire, M. J., Ward, B., Wardlaw III, M. C. and Watson, C. (2003). Utility of Remote Sensing in Predicting Crop and Soil Characteristics. Precision Agriculture, Kluwer Academic Publishers, vol. 4, pp. 359-384

Le Vine, D. M. \& Karam, M. A. (1996). Dependence of Attenuation in a Vegetation Canopy on Frequency and Plant Water Content; IEEE Transactions on Geoscience and Remote Sensing, vol. 34, n ${ }^{\circ}$ 5, pp. 1090-1096

Lymberopoulos, D. Lindsey, Q. and Savvides, A. (2005). An Empirical Analysis of Radio Signal Strength Variability in IEEE 802.15.4 Networks using Monopole Antennas. ENALAB Technical Report 050501. obtained from <http://www.eng.yale.edu/enalab/publications.htm>. Access: September/2005

McClave, J.T. \& Sincich, T. (2000). Statistics. Prentice Hall, 8 ed., 848 p.

Magri, A. Van Es, H. M, Glos, M. A. and Cox, W. J. (2005). Soil Test, Aerial Image and Yield Data as Inputs for Site-specific Fertility and Hybrid Management Under 
Maize. Precision Agriculture, Springer Science. pp. 87110.

Maity, S., Patnaik, C, Chakaborty, M. and Panigrahy, S. (2004). Analysis of Temporal Backscattering of Cotton Crops Using a Semiempirical Model. IEEE Transactions on Geoscience and Remote Sensing, vol. 42, pp. 577-587.

Mallarino, A. P. \& Wittry D. J. (2004). Efficacy of Grid and Zone Soil Sampling Approaches for Site-Specific Assessment of Phosphorus, Potassium, $\mathrm{pH}$, and Organic Matter. Precision Agriculture, Kluwer Academic Publishers, Netherlands, vol. 5, pp. 131-144.

Meissner, T. \& Wentz, F. J. (2004). The Complex Dielectric Constant of Pure and Sea Water Form Microwave Satellite Observations. IEEE Transactions on Geoscience and Remote Sensing, vol. 42, nº. 9, pp. 1836-1849.

National Research Council (1997) - Committee On Assessing Crop Yield: Site-specific Farming. Precision Agriculture In The 21st Century: Geospatial And Information Technologies In Crop Management. National Academy Press, Washington, USA. 149p.

Schmugge, T.J. \& Jackson, T.J. (1992). A Dielectric Model of Vegetation Effects on the Microwave Emission from Soils. IEEE Transactions on Geoscience and Remote Sensing, vol. 30, pp.757-760.

Schnell, L. (1993). Technology of Electrical Measurements. Ed. John Willey \& Sons, England, 409 p.

Tavakoli, A.; Sarabandi, K.; Ulaby, F.T. (1991). Horizontal Propagation Through Periodic Vegetation Canopies. IEEE Transactions on antennas and propagation, V. 39, $\mathrm{n}^{\circ}$ 7, pp. 1014-1023

Ulaby, F. T., Moore, R. K. and Fung, A. K. (1981). Microwave Remote Sensing: Active and Passive; vol. 1. Artech House, London, UK, $456 \mathrm{p}$.

Ulaby, F. T. \& Wilson, E. A. (1985). Microwave Attenuation Properties of Vegetation Canopies. IEEE Transactions on Geoscience and Remote Sensing, vol. GE23, $\mathrm{n}^{\circ} 5$, pp. 746-753.

Wigneron, J-P., Pardé, M., Waldteufel, P., Chanzy, A., Kerr, Y., Schmidl, S. and Skou, N. (2004). Characterizing the Dependence of Vegetation Model Parameters on Crop Structure, Incidence Angle, and Polarization at L-Band. IEEE Transactions on Geoscience and Remote Sensing, vol. 42, pp.416-424.

Willing, A., Matheus, K. and Wolisz, A. (2005); Wireless Technology in Industrial Networks; in Proceedings of the IEEE, vol. 93, $\mathrm{n}^{\circ} 6$, pp. 1130-1151. 